\title{
Capacidade de combinação de genitores de batata para caracteres de aparência e rendimento de tubérculos
}

\author{
Giovani Olegário da Silva ${ }^{1}$, Vicenti Gonçalves Ney², Laerte Reis Terres ${ }^{2}$, \\ Arione da Silva Pereira ${ }^{3}$ Fábio Akiyoshi Suinaga ${ }^{4}$
}

\section{RESUMO}

O objetivo deste trabalho foi estimar as capacidades de combinação de genitores de batata, em gerações iniciais de seleção. Os experimentos foram realizados em Pelotas e Canoinhas. Foram estudadas 12 famílias, derivadas de dois grupos de genitores, cruzados em esquema dialelo parcial (3 x 4) 'Eliza', 'C-1730-7-94' e 'C-1742-8-95'; 'Shepody', 'Asterix', 'White Lady’e 'Caesar'. As famílias foram avaliadas, na geração de plântula e na primeira geração de campo, para caracteres componentes de aparência e rendimento de tubérculos. Os dados foram submetidos às análises de variância e dialélica parcial. No conjunto de caracteres avaliados, verificou-se superioridade de efeitos significativos para a capacidade geral de combinação, em relação à capacidade específica de combinação, indicando predominância de efeitos aditivos dos genes, no controle dos caracteres. Em relação à capacidade geral de combinação, 'White Lady' é o genitor mais destacado positivamente, contribuindo com genes de ação aditiva para a melhoria, tanto dos caracteres que compõem a aparência dos tubérculos, quanto dos caracteres de rendimento. Quanto à capacidade específica de combinação, o cruzamento ('C1730-7-94' x 'White Lady') é o mais indicado para a geração de famílias superiores quanto a caracteres de aparência e a caracteres componentes do rendimento de tubérculos.

Palavras-chave: Solanum tuberosum L., geração precoce, análise dialélica parcial.

\section{ABSTRACT}

\section{Combining ability of potato parents for tuber appearance and yield traits}

The objective of this work was to estimate the general and specific combining ability of potato parents in early generation of selection. The experiments were carried out at the municipality of Pelotas and Canoinhas. Twelve potato families derived from two groups of parents crossed in a 3 x 4 partial mating design were studied: 'Eliza', 'C-1730-7-94', 'C-1742-8-95' and 'Shepody', 'Asterix', 'White Lady', 'Caesar'. The families were evaluated at the seedling stage and in the first field generation for tuber appearance traits and tuber yield traits. The data were submitted to variance analysis, and partial diallel analysis. In the set of traits there was superiority of significant effects for general combining ability in relation to specific combining ability. This suggests a predominance of additive effects of the genes in the control of these traits. Regarding the general combining ability, 'White Lady' is the most prominent parent, contributing with genes of additive action for the improvement of tuber appearance traits and yield traits. As for the specific combining ability, the cross 'C1730-7-94' $\mathrm{x}$ 'White Lady' is the most suitable for the generation of superior families for tuber appearance traits and yield traits.

Key words: Solanum tuberosum L., early generation, partial diallel analysis.

Recebido para publicação em 16/08/2012 e aprovado em 24/05/2013.

'Engenheiro-Agrônomo, Doutor. Embrapa Hortaliças/SPM, Rodovia BR 280, Km 231, 1151, Caixa Postal 317, 89460-000, Canoinhas, Santa Catarina, Brasil. olegario@embrapa.br (autor para correspondência).

${ }^{2}$ Engenheiro-Agrônomo. Departamento de Agronomia, Universidade Federal de Pelotas, Campus Universitário s/n, Caixa Postal 354, 96015-360, Pelotas, Rio Grande do Sul, Brasil. vicentig@gmail.com; laerte_terres@yahoo.com.br

${ }^{3}$ Engenheiro-Agrônomo, Doutor. Embrapa Clima Temperado, Rodovia BR 392, Km 78, Caixa Postal 403, 96001-970, Pelotas, Rio Grande do Sul, Brasil. arione.pereira@cpact.embrapa.br

${ }^{4}$ Engenheiro-Agrônomo, Doutor. Embrapa Hortaliças, Rodovia BR 060, Km 09, Caixa Postal 218, 70359-970, Brasília, Distrito Federal, Brasil. fabio.suinaga@embrapa.br 


\section{INTRODUÇÃO}

A alta heterozigosidade e a herança tetraploide da batata Solanum tuberosum dificultam a aplicação de vários modelos biométricos (Gopal, 1998), pelo fato de a teoria genético-biométrica pressupor que a herança é dissômica e a população, das quais os pais são amostrados, está em equilíbrio pan-mítico, ou consiste em linhagens endogâmicas (Barbosa \& Pinto, 1998).

Para a seleção de genitores, uma das metodologias mais eficientes e comumente utilizadas em programas de melhoramento genético é a análise dialélica, a qual propicia estimativas de parâmetros úteis à seleção de genitores para hibridação e ao entendimento da ação dos genes envolvidos na determinação dos caracteres e da existência de heterose (Cruz et al., 2004), proporcionando, assim, grandes avanços para a seleção (Jaramillo et al., 2005).

Existem vários métodos para a análise de cruzamentos dialélicos, sendo o proposto por Griffing (1956) amplamente empregado. Esse método proporciona informações a respeito da capacidade geral de combinação dos genitores (CGC), que está relacionada com a concentração de genes predominantemente aditivos, e da capacidade específica de combinação (CEC), relacionada com a concentração de genes de efeito basicamente não aditivo (dominância e epistasia) (Castiglioni et al., 1999).

A dificuldade de se estudar um grande número de genitores no sistema completo fez que adaptações, como o esquema de dialelos parciais, fossem desenvolvidas. Os dialelos parciais envolvem a avaliação de genitores dispostos em dois grupos, pertencentes, ou não, a um conjunto comum, sendo as inferências feitas para cada grupo (Cruz et al., 2004).

Silva et al. (2009) verificaram que as capacidades de combinação dos caracteres rendimento de tubérculos, número de tubérculos por planta e massa média de tubérculos podem ser estimadas por meio de dialelo parcial, para as geração de plântula e primeira geração de campo. Da mesma forma, Silva et al. (2008) relataram que, para os caracteres aspereza da película, sobrancelha, achatamento, curvatura, apontamento e aparência de tubérculo, avaliados na primeira e segunda gerações de campo, as estimativas de capacidade de combinação foram eficientes na identificação das melhores combinações de genitores, por meio da análise dialélica conjunta.

A análise dialélica parcial foi também utilizada em batata por Barbosa \& Pinto (1998), com cruzamentos entre grupos formados por cultivares nacionais e importados, para os caracteres produção total de tubérculo por planta; peso médio de tubérculos graúdos; peso médio de tubérculos médios; percentagem da produção total de tubérculos graúdos; número de tubérculos graúdos e médios por planta e densidade relativa de tubérculos.
As informações disponíveis, no que se refere à utilização de análise dialélica em batata, principalmente, para os caracteres pesquisados neste estudo, é limitada a poucos trabalhos, provavelmente por dificuldade de formação de combinações, entre vários genitores, no formato de uma análise dialélica. Pois, dependendo da combinação, a obtenção de frutos e sementes é difícil, enquanto, para outros, a compatibilidade é maior.

O objetivo deste trabalho foi estimar as capacidades de combinação de genitores de batata, em gerações iniciais de seleção, em dois locais de cultivo.

\section{MATERIAL E MÉTODOS}

Os experimentos foram realizados nos campos experimentais da Embrapa Clima Temperado, em Pelotas $\left(31^{\circ} \mathrm{S}\right.$, $52^{\circ} \mathrm{W}, 50 \mathrm{~m}$ a.n.m.), RS, e do Escritório de Negócios da Embrapa Transferência de Tecnologia, em Canoinhas $\left(26^{\circ}\right.$ S, $50^{\circ} \mathrm{W}, 765 \mathrm{~m}$ a.n.m.), SC. Foram avaliadas 12 famílias híbridas de batata, originadas de cruzamentos controlados entre dois grupos de genitores de batata, escolhidos ao acaso, em modelo parcial de dois grupos de genitores (3x4), conforme o modelo do "experimento 2 " de Comstock \& Robinson (1948). Este modelo envolve a avaliação de genitores dispostos em dois grupos, pertencentes, ou não, a um conjunto comum (Cruz et al., 2004).

Os cruzamentos proporcionaram a obtenção de doze famílias para avaliação. O grupo 1 foi formado pelos genitores: Eliza, C-1730-7-94 e C-1742-8-95; e, o grupo 2, por: Shepody, Asterix, White Lady e Caesar.

Em cada local, Pelotas, RS, e Canoinhas, SC, na safra de primavera 2010/2011, foi produzida a geração de plântula, em casa de vegetação. As sementes botânicas foram germinadas em sementeiras e as plântulas transplantadas para sacos plásticos, contendo dois litros de substrato, para produção de minitubérculos. As plântulas foram distribuídas em blocos, ao acaso, com três repetições. Cada parcela foi composta de uma amostra de 25 plântulas, escolhidas aleatoriamente, para representar cada cruzamento. O espaçamento entre plantas e entre linhas foi $0,10 \mathrm{~m}$. As plântulas foram mantidas nessas condições até a colheita, que ocorreu aos 77 dias, quando os tubérculos foram transportados para instalações apropriadas, para serem efetuadas as avaliações. Após as avaliações, os tubérculos foram armazenados em câmara fria, $\mathrm{a} 4^{\circ} \mathrm{C}$.

Também, em cada local de cultivo, na safra de primavera de 2011/2012, foi produzida a primeira geração de campo. Um tubérculo de tamanho médio de cada genótipo foi plantado a campo, utilizando-se do mesmo delineamento experimental da safra anterior. Aos 95 dias, as plantas foram colhidas separadamente e realizadas as avaliações nos tubérculos. 
Os caracteres de aparência de tubérculo, avaliados em ambas as gerações, foram: aspereza de tubérculo (1- áspero, 9- liso), profundidade de olho (1- profundo, 9- superficial), proeminência de sobrancelha (1- proeminente, 9- superficial), formato de tubérculo (1- redondo, 9- alongado), uniformidade de formato de tubérculo (1desuniforme, 9- uniforme), apontamento de tubérculo (1apontado, 9- não apontado), curvatura de tubérculo (1curvado, 9- não curvado), achatamento de tubérculo (1achatado, 9- não achatado), tamanho de tubérculo (1pequeno, 9- grande), uniformidade de tamanho de tubérculo (1- desuniforme, 9- uniforme) e aparência geral de tubérculo (1- aparência geral ruim, 9- boa aparência geral). Foram considerados tubérculos de boa aparência aqueles que apresentaram, conjuntamente, pele lisa, olhos pouco profundos, sobrancelha superficial, boa uniformidade de formato, não apontado, não curvado, não achatado e boa uniformidade de tamanho. Os caracteres de rendimento avaliados foram: número de tubérculos por planta e massa total de tubérculos por planta (g/planta). A massa média de tubérculos $(\mathrm{g})$ foi derivada dos dados.

Os dados foram verificados quanto à normalidade de distribuição dos erros (Lilliefors) (Campos, 1983) e homogeneidade de variância (teste de Bartllet) (Steel \& Torrie, 1980). Posteriormente, para cada local, foram realizadas análises de variância, de cada geração e, conjuntamente, para as gerações de plântula e primeira de campo; análise dialélica parcial, de cada geração e, conjuntamente, para os caracteres que não apresentaram interação (genótipo x geração).

Geração e genótipos foram considerados efeitos fixos. As análises foram realizadas com a utilização do programa GENES (Cruz, 2006).

\section{RESULTADOS E DISCUSSÃO}

Na averiguação da normalidade dos dados, o caráter aspereza de tubérculo, para ambas as gerações de plântula, e, primeira geração de campo, em Pelotas, RS, e os caracteres apontamento de tubérculo e curvatura de tubérculo, para a geração de plântula, e o caráter aparência geral, para a primeira geração de campo, em Canoinhas, não apresentaram distribuição normal de erros, mesmo após transformação e, portanto, foram desconsiderados das análises estatísticas.

As análises de variância revelaram diferenças significativas $(\mathrm{p}<0,05)$ entre famílias, para a maioria dos caracteres, gerações e locais, com exceção de tamanho de tubérculo, nas duas gerações, uniformidade de tamanho de tubérculos, na geração de plântula, formato de tubérculo e apontamento de tubérculo, na primeira geração de campo, em Pelotas; e os caracteres formato, apontamento e achatamento de tubérculo, na primeira geração de campo, em Canoinhas.
A análise de variância conjunta das duas gerações mostrou interação significativa entre família x geração, para formato, apontamento, uniformidade de tamanho, número de tubérculos, massa de tubérculos por planta e massa média de tubérculos por planta, em Pelotas, e para família x geração, para formato, uniformidade de formato, achatamento de tubérculo, número, massa e massa média de tubérculos, em Canoinhas. Desta forma, foram considerados, separadamente, para cada geração, na apresentação e discussão dos resultados.

No conjunto de caracteres avaliados, considerandose ambos os locais e gerações, verificou-se superioridade de efeitos significativos para a capacidade geral de combinação (CGC), em relação à capacidade específica de combinação (CEC), indicando predominância de efeitos aditivos dos genes, no controle dos caracteres. Isto sugere que o desempenho das progênies para estes caracteres pode ser previsto sem a realização dos cruzamentos e avaliação dos híbridos (Barbosa \& Pinto, 1998). Gopal (1998) verificou a predominância de CEC significativas em batata. Killick (1977) revisou vários trabalhos, encontrando diferentes resultados em relação às predominâncias de CGC ou CEC. Bradshaw \& Mackay (1994), em ampla revisão, relataram que, de modo geral, os valores de CGC e CEC têm influenciado, em proporções variadas, todos os caracteres de importância agronômica em batata. Neele et al. (1991) sugeriram que a CEC tende a ser mais importante que a CGC em cruzamentos envolvendo pais relacionados. Tai (1976) propôs o mesmo para caracteres que têm sido submetidos à seleção direcional contínua. Portanto, pode-se conceber que a importância da CGC ou CEC depende da população e dos caracteres considerados, e, segundo Maris (1989), depende também do desenho experimental e, ou, das condições ambientais.

As estimativas de CGC conjunta das duas gerações foram significativas para o caráter profundidade de olho, para o grupo 2 de genitores, em Pelotas, sendo 'Caesar', o genitor que mais contribuiu para o aumento das estimativas deste caráter, ou seja, para a diminuição da profundidade dos olhos dos tubérculos (Tabela 1). Por outro lado, 'Shepody' seria o genitor menos recomendado para cruzamentos, objetivando a formação de famílias com olhos rasos.

Em relação à sobrancelha, 'Caesar', com valores positivos e estáveis de CGC, para as duas gerações e em ambos os locais de avaliação, para a obtenção de famílias com menor proeminência de sobrancelha, seria também o genitor mais recomendado para esse caráter (Tabela 1).

Para o caráter uniformidade de formato, no conjunto das duas gerações, em Pelotas, 'White Lady' foi o melhor genitor do grupo 2, enquanto 'Asterix' contribuiu para tubérculos mais desuniformes em relação a formato em suas progênies (Tabela 1). 
Quanto ao caráter curvatura, nas duas gerações, em Pelotas, a CGC foi significativa para todos os genitores do grupo 2 (Tabela 1). 'White Lady' deu a maior contribuição para a obtenção de tubérculos menos curvados, enquanto ocorreu o oposto, quanto a 'Asterix' e 'Caesar'.
Para o caráter achatamento, o genitor 'C1730-7-94', do grupo 1, contribuiu positivamente para a diminuição do achatamento dos tubérculos, quando cruzado com os genitores do grupo 2, sendo, portanto, recomendado para cruzamentos visando a esse caráter (Tabela 1). O contrá-

Tabela 1. Capacidade geral de combinação de sete genitores de batata para caracteres de aparência de tubérculos avaliados em dois locais

\begin{tabular}{|c|c|c|c|c|c|c|}
\hline \multirow{3}{*}{ Genitor } & \multicolumn{6}{|c|}{ Caracteres $^{1}$} \\
\hline & \multicolumn{6}{|c|}{ Pelotas, RS } \\
\hline & OLH & SOB & UFO & CUR & $\mathrm{ACH}$ & APA \\
\hline Eliza & $-0,13$ & $-0,14$ & $-0,19$ & $-0,15$ & $-0,26^{*}$ & $-0,16$ \\
\hline C1730-7-94 & 0,02 & 0,09 & 0,10 & 0,22 & $0,22 *$ & $-0,03$ \\
\hline C1742-8-95 & 0,11 & 0,06 & 0,09 & $-0,08$ & $0,05^{*}$ & 0,19 \\
\hline Shepody & $-0,55^{*}$ & $-0,55^{*}$ & $0,05^{*}$ & $0,02 *$ & $-0,20 *$ & $-0,14^{*}$ \\
\hline Asterix & $-0,19 *$ & $-0,27^{*}$ & $-0,24 *$ & $-0,18^{*}$ & $0,23 *$ & $-0,08^{*}$ \\
\hline White Lady & $0,12 *$ & $0,18 *$ & $0,34 *$ & $0,39 *$ & $0,25^{*}$ & $0,38^{*}$ \\
\hline \multirow[t]{3}{*}{ Caesar } & $0,61 *$ & $0,63 *$ & $-0,15^{*}$ & $-0,23 *$ & $-0,29 *$ & $-0,16^{*}$ \\
\hline & \multicolumn{6}{|c|}{ Canoinhas, SC } \\
\hline & ASP & OLH & & & TAM & UTA \\
\hline Eliza & 0,16 & 0,25 & & & $-0,12$ & $-0,08$ \\
\hline C1730-7-94 & $-0,19$ & 0,07 & & & 0,14 & 0,00 \\
\hline C1742-8-95 & 0,03 & $-0,32$ & & & $-0,02$ & 0,08 \\
\hline Shepody & $-0,34$ & 0,18 & & & $-0,08$ & $-0,22$ \\
\hline Asterix & 0,10 & $-0,31$ & & & 0,06 & 0,18 \\
\hline White Lady & $-0,29$ & 0,11 & & & 0,13 & 0,13 \\
\hline Caesar & 0,54 & 0,01 & & & $-0,10$ & $-0,08$ \\
\hline
\end{tabular}

${ }^{1}$ OLH: profundidade do olho; SOB: sobrancelha; UFO: uniformidade de formato; CUR: curvatura; ACH: achatamento; APA: aparência; ASP: aspereza da película; TAM: tamanho; UTA: uniformidade de tamanho.

* Significativo a $5 \%$ pelo teste $\mathrm{t}$.

Tabela 2. Capacidade geral de combinação de sete genitores de batata para caracteres de aparência e de produtividade de tubérculos avaliados na geração de plântula e primeira geração de campo, em Pelotas, RS

\begin{tabular}{|c|c|c|c|c|c|c|}
\hline \multirow{3}{*}{ Genitor } & \multicolumn{6}{|c|}{ Caracteres $^{1}$} \\
\hline & FOR $^{1}$ & APO & UTA & NTU & MAS & MAM \\
\hline & \multicolumn{6}{|c|}{ Geração de plântula } \\
\hline Eliza & $-0,15$ & $-0,13^{*}$ & $0,02 *$ & 0,00 & 1,22 & 0,32 \\
\hline C1730-7-94 & 0,12 & $0,29 *$ & $-0,21 *$ & $-0,31$ & $-1,41$ & 0,31 \\
\hline C1742-8-95 & 0,03 & $-0,16^{*}$ & $0,19 *$ & 0,31 & 0,19 & $-0,63$ \\
\hline Shepody & $0,06 *$ & $-0,25^{*}$ & $0,23 *$ & $-0,33$ & 1,87 & 1,38 \\
\hline Asterix & $0,50 *$ & $-0,02 *$ & $-0,09 *$ & 0,48 & 2,75 & $-0,18$ \\
\hline White Lady & $-0,55^{*}$ & $0,42 *$ & $0,22 *$ & 0,49 & 2,41 & $-0,43$ \\
\hline \multirow[t]{2}{*}{ Caesar } & $-0,01 *$ & $-0,15^{*}$ & $-0,35^{*}$ & $-0,64$ & $-7,03$ & $-0,77$ \\
\hline & \multicolumn{6}{|c|}{ Primeira geração de campo } \\
\hline Eliza & 0,20 & $-0,10$ & $-0,34 *$ & $-0,57$ & 4,53 & $3,92 *$ \\
\hline C1730-7-94 & $-0,30$ & 0,10 & $0,04 *$ & 0,29 & $-11,30$ & $-2,87 *$ \\
\hline C1742-8-95 & 0,10 & 0,00 & $0,31 *$ & 0,28 & 6,77 & $-1,04 *$ \\
\hline Shepody & $-0,21 *$ & $0,24 *$ & 0,09 & $-0,04 *$ & $57,94 *$ & $7,05^{*}$ \\
\hline Asterix & $0,30 *$ & $-0,11^{*}$ & $-0,26$ & $0,40^{*}$ & $-22,03 *$ & $-4,80 *$ \\
\hline White Lady & $-0,37 *$ & $0,06^{*}$ & 0,16 & $0,99 *$ & $58,21 *$ & $0,78^{*}$ \\
\hline Caesar & $0,28 *$ & $-0,18^{*}$ & 0,01 & $-1,35^{*}$ & $-94,12 *$ & $-3,04 *$ \\
\hline
\end{tabular}

${ }^{1}$ FOR: formato; APO: apontado; UTA: uniformidade de tamanho; NTU: número de tubérculos; MAS: massa de tubérculos; MAM: massa média de tubérculos.

*Significativo a $5 \%$ pelo teste $\mathrm{t}$.

Rev. Ceres, Viçosa, v. 60, n.4, p. 489-497, jul/ago, 2013 
rio foi verificado para 'Eliza'. No grupo 2, 'White Lady' teve os maiores valores de CGC, enquanto 'Shepody' e 'Caesar' apresentaram os maiores valores negativos, ou seja, contribuíram para maior achatamento de tubérculos.

Quanto ao caráter aparência, no conjunto das gerações, 'White Lady' apresentou os maiores valores positivos de CGC (Tabela 1).

Para os caracteres aspereza e tamanho de tubérculo, não houve estimativas de CGC significativas dos genitores (Tabela 1).

As estimativas de CGC, para Pelotas, nas gerações de plântula e primeira de campo, estão apresentadas na (Tabela 2). Para o caráter formato de tubérculo, as estimativas foram significativas para os genitores do grupo 2, em ambas as gerações. Neste grupo, 'Asterix' apresentou os maiores valores de CGC positivos, portanto, favoreceu a geração de famílias com tubérculos mais alongados, ao passo que 'White Lady' contribuiu para geração de tubérculos mais arredondados. Pode-se verificar que ambos os cultivares contribuíram com genes de efeitos aditivos, uma vez que 'Asterix' apresenta tubérculos alongados e, 'White Lady', tubérculos ovais.

Para o caráter apontamento de tubérculo, nos experimentos realizados em Pelotas, as estimativas de CGC foram significativas (Tabela 2). O melhor genitor do grupo 1, para este caráter, na geração de plântula, foi 'C1730-7-94', enquanto, no grupo 2, foi 'White Lady', o qual apresentou valores positivos em ambas as gerações. 'Caesar' tam- bém foi estável nas duas gerações, porém com valores negativos, ou seja, contribuindo para tubérculos mais apontados.

Quanto à uniformidade de tamanho, no grupo 1, 'C1742-8-95' foi o genitor mais estável e com valores positivos maiores, na geração de plântula e na primeira geração de campo, em Pelotas (Tabela 2). No grupo 2, na geração de plântula, também em Pelotas, 'Shepody' e 'White Lady' tiveram os melhores desempenhos, enquanto 'Caesar' apresentou o maior valor negativo de CGC, ou seja, favorecendo a redução na uniformidade de tamanho de tubérculos.

As estimativas de CGC para Canoinhas, na geração de plântula e primeira geração de campo estão apresentadas na Tabela 3. Para os genitores do grupo 1, as estimativas para formato de tubérculo foram significativas apenas na geração de plântula. O genitor 'C1730-7-94' contribuiu para a geração de plantas com tubérculos mais alongados, enquanto 'Eliza' contribuiu para plantas com tubérculos mais arredondados.

Quanto ao caráter uniformidade de formato, 'Eliza' mostrou-se o melhor genitor no grupo 1 , em ambas as gerações, em Canoinhas (Tabela 3).

Para o caráter achatamento de tubérculo, na geração de plântula, o genitor do grupo 1 'C1730-7-94' contribuiu positivamente para a diminuição do achatamento dos tubérculos (Tabela 3). Portanto, esse genitor seria recomendado para cruzamentos visando a esse propósito. O con-

Tabela 3. Capacidade geral de combinação de sete genitores de batata para caracteres de aparência e de produtividade de tubérculos avaliados na geração de plântula e primeira geração de campo, em Canoinhas, SC

\begin{tabular}{|c|c|c|c|c|c|c|c|c|}
\hline \multirow{3}{*}{ Genitor } & \multicolumn{8}{|c|}{ Caracteres } \\
\hline & \multicolumn{8}{|c|}{ Geração de plântula } \\
\hline & FOR $^{1}$ & UFO & $\mathrm{ACH}$ & APA & & NTU & MAS & MAM \\
\hline Eliza & $-0,65^{*}$ & $0,30 *$ & $-0,14^{*}$ & $-0,22$ & & $0,06^{*}$ & $-0,15$ & 0,04 \\
\hline C1730-7-94 & $0,91 *$ & $-0,46^{*}$ & $0,33^{*}$ & 0,23 & & $-0,38 *$ & 0,25 & 0,32 \\
\hline C1742-8-95 & $-0,26 *$ & $0,17 *$ & $-0,19 *$ & $-0,01$ & & $0,32 *$ & $-0,10$ & $-0,36$ \\
\hline Shepody & 0,44 & 0,31 & $-0,41 *$ & $-0,36$ & & $-0,10^{*}$ & $-0,08^{*}$ & 0,02 \\
\hline Asterix & $-0,38$ & $-0,30$ & $0,09 *$ & 0,00 & & $-0,48 *$ & $-1,14^{*}$ & 0,17 \\
\hline White Lady & 0,24 & $-0,04$ & $0,44^{*}$ & 0,42 & & $0,48 *$ & $0,79 *$ & $-0,18$ \\
\hline \multirow[t]{3}{*}{ Caesar } & $-0,30$ & 0,03 & $-0,11 *$ & $-0,06$ & & $0,09^{*}$ & $0,43^{*}$ & 0,00 \\
\hline & \multicolumn{8}{|c|}{ Primeira geração de campo } \\
\hline & FOR & UFO & APO & CUR & $\mathrm{ACH}$ & NTU & MAS & MAM \\
\hline Eliza & 0,05 & $0,36^{*}$ & 0,17 & 0,10 & 0,01 & $-0,37$ & $-8,87 *$ & $3,13^{*}$ \\
\hline C1730-7-94 & 0,02 & $0,27 *$ & $-0,20$ & $-0,13$ & $-0,04$ & 0,03 & $56,17^{*}$ & $9,26^{*}$ \\
\hline C1742-8-95 & $-0,07$ & $-0,63 *$ & 0,03 & 0,02 & 0,03 & 0,35 & $-47,30 *$ & $-12,39 *$ \\
\hline Shepody & $-0,06$ & 0,49 & $-0,07$ & $-0,13$ & 0,03 & $-0,76^{*}$ & 2,71 & $9,83 *$ \\
\hline Asterix & $-0,07$ & $-0,16$ & 0,33 & 0,30 & $-0,08$ & $0,49 *$ & $-13,67$ & $-8,01^{*}$ \\
\hline White Lady & 0,17 & $-0,07$ & 0,02 & $-0,18$ & 0,08 & $0,79^{*}$ & 44,10 & $-2,11 *$ \\
\hline Caesar & $-0,04$ & $-0,26$ & $-0,28$ & 0,02 & $-0,03$ & $-0,52 *$ & $-33,14$ & $0,29 *$ \\
\hline
\end{tabular}

'FOR: formato; UFO: uniformidade de formato; ACH: achatado; APA: aparência; NTU: número de tubérculos; MAS: massa de tubérculos; MAM: massa média de tubérculos; APO: apontado; CUR: curvo.

*Significativo a $5 \%$ pelo teste $\mathrm{t}$. 
trário foi verificado para 'Eliza' e 'C1742-8-95'. No grupo 2, 'White Lady' teve o maior valor de CGC, enquanto 'Shepody' e 'Caesar' apresentaram os maiores valores negativos, ou seja, contribuíram para maior achatamento de tubérculos.

Sendo assim, conforme os valores de CGC para o conjunto de caracteres componentes da aparência geral, podese verificar que 'White Lady' foi o genitor que apresentou os maiores valores de CGC, ou seja, contribuiu com genes de efeitos aditivos, para a melhoria dos caracteres que compõem a aparência dos tubérculos. Por outro lado, 'Caesar' foi o pior genitor para aparência geral de tubérculo, exceto para profundidade de olho e sobrancelha de tubérculo. No grupo 1, não foi detectado nenhum genitor para a melhoria dos caracteres componentes da aparência.

Para os caracteres de rendimento de tubérculos (número, massa e massa média), em Canoinhas, para os genitores do grupo 1 , pode-se verificar que o genitor ' $\mathrm{C}$ 1742-8-95' apresentou os maiores valores positivos, para número de tubérculo na geração de plântula, enquanto 'C1730-7-94' teve os maiores valores negativos, ou seja, contribuindo para um menor número de tubérculos (Tabela 3). Diferentemente do relatado por Silva et al. (2009), em estudo com outras combinações, o genitor 'Eliza' não apresentou valor elevado de CGC para número de tubérculos. No grupo 2, 'White Lady' foi o genitor com os maiores valores de CGC para número de tubérculos, na geração de plântula e na primeira geração de campo. Esse genitor também apresentou as maiores estimativas de CGC, na primeira geração de campo, em Pelotas. Pode-se verificar, também, que, na primeira geração de campo, a classificação dos genitores, em relação à CGC positiva, ou negativa, para esse caráter, em Canoinhas, foi muito semelhante à de Pelotas (Tabelas 2 e 3).

Para o caráter massa de tubérculo, na geração de plântula, em Canoinhas, 'White Lady' apresentou a maior CGC, enquanto 'Asterix' teve o menor valor (Tabela 3). O comportamento desses dois cultivares também foi seme-

Tabela 4. Capacidade específica de combinação de sete genitores de batata para caracteres de aparência de tubérculo avaliados em dois locais

\begin{tabular}{|c|c|c|c|c|c|c|}
\hline \multirow{3}{*}{ Cruzamento } & \multicolumn{6}{|c|}{ Caracteres } \\
\hline & \multicolumn{6}{|c|}{ Pelotas, RS } \\
\hline & OLH $^{1 *}$ & SOB* & UFO & CUR* & $\mathrm{ACH}$ & APA \\
\hline Eliza x Shepody & 0,49 & 0,51 & 0,07 & $-0,03$ & 0,11 & 0,09 \\
\hline Eliza x Asterix & $-0,21$ & $-0,08$ & $-0,20$ & $-0,14$ & $-0,12$ & $-0,05$ \\
\hline Eliza x White Lady & $-0,47$ & $-0,48$ & 0,37 & 0,41 & 0,11 & 0,17 \\
\hline Eliza x Caesar & 0,19 & 0,06 & $-0,24$ & $-0,24$ & $-0,10$ & $-0,21$ \\
\hline C1730-7-94 x Shepody & $-0,79$ & $-0,72$ & 0,17 & 0,40 & 0,23 & $-0,02$ \\
\hline C1730-7-94 x Asterix & 0,27 & 0,21 & 0,02 & $-0,37$ & $-0,06$ & $-0,03$ \\
\hline C1730-7-94 x White Lady & 0,21 & 0,24 & $-0,15$ & $-0,04$ & 0,01 & $-0,02$ \\
\hline C1730-7-94 x Caesar & 0,30 & 0,28 & $-0,04$ & 0,01 & $-0,18$ & 0,07 \\
\hline C1742-8-95 x Shepody & 0,30 & 0,22 & $-0,23$ & $-0,37$ & $-0,34$ & $-0,07$ \\
\hline C1742-8-95 x Asterix & $-0,06$ & $-0,12$ & 0,18 & 0,51 & 0,19 & 0,08 \\
\hline C1742-8-95 x White Lady & 0,26 & 0,24 & $-0,23$ & $-0,36$ & $-0,12$ & $-0,15$ \\
\hline \multirow[t]{3}{*}{ C1742-8-95 x Caesar } & $-0,49$ & $-0,33$ & 0,28 & 0,22 & 0,27 & 0,14 \\
\hline & \multicolumn{6}{|c|}{ Canoinhas, SC } \\
\hline & $\mathbf{A S P}^{1}$ & OLH & SOB & TAM & UTA & - \\
\hline Eliza x Shepody & 0,61 & $-0,35$ & 0,18 & $-0,12$ & 0,09 & - \\
\hline Eliza x Asterix & $-0,30$ & 0,68 & 0,34 & $-0,22$ & $-0,06$ & - \\
\hline Eliza x White Lady & 0,38 & $-0,21$ & $-0,24$ & 0,25 & 0,09 & - \\
\hline Eliza x Caesar & $-0,70$ & $-0,12$ & $-0,29$ & 0,09 & $-0,12$ & - \\
\hline C1730-7-94 x Shepody & $-0,38$ & 0,30 & $-0,23$ & 0,04 & $-0,19$ & - \\
\hline C1730-7-94 x Asterix & 0,46 & $-0,44$ & $-0,13$ & 0,04 & 0,13 & - \\
\hline C1730-7-94 x White Lady & $-0,40$ & 0,16 & 0,03 & $-0,08$ & $-0,06$ & - \\
\hline C1730-7-94 x Caesar & 0,32 & $-0,03$ & 0,32 & 0,00 & 0,13 & - \\
\hline C1742-8-95 x Shepody & $-0,23$ & 0,05 & 0,04 & 0,08 & 0,10 & - \\
\hline C1742-8-95 x Asterix & $-0,16$ & $-0,24$ & $-0,22$ & 0,19 & $-0,07$ & - \\
\hline C1742-8-95 x White Lady & 0,02 & 0,05 & 0,20 & $-0,17$ & $-0,03$ & - \\
\hline C1742-8-95 x Caesar & 0,38 & 0,15 & $-0,03$ & $-0,10$ & $-0,01$ & - \\
\hline
\end{tabular}

${ }^{1} \mathrm{OLH}$ : profundidade de olho; SOB: sobrancelha; UFO: uniformidade de formato; CUR: curvo; ACH: achatado; APA: aparência; ASP: aspereza; TAM: tamanho; UTA: uniformidade de tamanho.

*Significativo a $5 \%$ pelo teste $\mathrm{t}$.

Rev. Ceres, Viçosa, v. 60, n.4, p. 489-497, jul/ago, 2013 
lhante, para a primeira geração de campo, em Pelotas. $\mathrm{Na}$ primeira geração de campo, em Pelotas, 'Caesar' demonstrou contribuição indesejável de genes aditivos para a diminuição de massa de tubérculos, enquanto, no grupo 1 , o genitor 'C1730-7-94' contribuiu para maior CGC do caráter massa de tubérculos, na primeira geração de campo, em Canoinhas, e 'C1742-8-95' teve o pior desempenho (Tabelas 2 e 3).

Em relação à massa média de tubérculos, na primeira geração de campo, o genitor do grupo 1 com maior valor de CGC e estabilidade nos dois locais de avaliação foi 'Eliza', enquanto, no grupo 2, foi 'Shepody' (Tabelas 2 e 3). Por outro lado, 'Asterix' teve os maiores valores negativos nos dois locais, contribuindo com efeitos negativos de CGC para massa média de tubérculos, ou seja, favorecendo tubérculos com pequena massa média. Os resultados indicam que 'White Lady' contribui com genes aditivos para esse caráter, enquanto 'Asterix' apresenta efeito contrário, confirmando os resultados de Silva et al. (2009).
Para o caráter formato de tubérculo, na geração de plântula, em ambos os locais, o cruzamento 'C1730-7-94' x 'Asterix' proporcionou as maiores estimativas positivas de CEC, favorecendo a formação de tubérculos mais alongados, enquanto o cruzamento 'C1742-08-95' x 'Asterix' foi o mais favorável para tubérculos arredondados. No entanto, a simples significância da CEC não basta para recomendar um cruzamento, é necessário que pelo menos um dos genitores apresente CGC elevada (Cruz et al., 2004). Assim, para tubérculos alongados, o cruzamento 'Asterix' $\mathrm{x}$ 'C1730-7-94' seria o mais adequado, pois, ambos os genitores apresentaram valores positivos de CGC.

Para o conjunto de caracteres componentes da aparência de tubérculo, pode-se verificar que os cruzamentos de 'C1730-7-94' com 'White Lady' e 'Caesar', e o cruzamento de 'C1742-8-95' e 'Asterix' foram aqueles que apresentaram o maior número de estimativas de CEC positivas, para gerações e locais de avaliação (Tabelas 4, 5 e 6). O cruzamento 'C1730-7-94' x 'White Lady' teve bom

Tabela 5. Capacidade específica de combinação de sete genitores de batata para caracteres de aparência e de produtividade de tubérculos avaliados na geração de plântula e primeira geração de campo, em Pelotas, RS

\begin{tabular}{|c|c|c|c|c|c|c|}
\hline \multirow{3}{*}{ Cruzamento } & \multicolumn{6}{|c|}{ Caracteres } \\
\hline & \multicolumn{6}{|c|}{ Geração de plântula } \\
\hline & FOR $^{1 *}$ & APO* & UTA & NTU & MAS & MAM \\
\hline Eliza x Shepody & 0,48 & $-0,22$ & 0,32 & $-0,13$ & $-1,58$ & $-0,04$ \\
\hline Eliza $x$ Asterix & 0,13 & 0,04 & $-0,14$ & $-0,04$ & 1,56 & 0,61 \\
\hline Eliza x White Lady & $-0,54$ & 0,53 & 0,11 & 0,06 & 1,43 & 0,21 \\
\hline Eliza x Caesar & $-0,07$ & $-0,35$ & $-0,29$ & 0,11 & $-1,40$ & $-0,79$ \\
\hline C1730-7-94 x Shepody & $-0,70$ & 0,73 & 0,07 & 0,39 & 0,69 & $-0,76$ \\
\hline C1730-7-94 x Asterix & 0,19 & $-0,51$ & 0,01 & $-0,36$ & $-3,87$ & $-0,44$ \\
\hline C1730-7-94 x White Lady & $-0,02$ & $-0,33$ & $-0,16$ & 0,04 & 1,07 & 0,12 \\
\hline C1730-7-94 x Caesar & 0,53 & 0,11 & 0,07 & $-0,08$ & 2,11 & 1,08 \\
\hline C1742-8-95 x Shepody & 0,22 & $-0,51$ & $-0,39$ & $-0,26$ & 0,90 & 0,80 \\
\hline C1742-8-95 x Asterix & $-0,32$ & 0,48 & 0,13 & 0,40 & 2,30 & $-0,17$ \\
\hline C1742-8-95 x White Lady & 0,56 & $-0,20$ & 0,05 & $-0,10$ & $-2,49$ & $-0,33$ \\
\hline \multirow[t]{3}{*}{ C1742-8-95 x Caesar } & $-0,46$ & 0,24 & 0,22 & $-0,03$ & $-0,70$ & $-0,29$ \\
\hline & \multicolumn{6}{|c|}{ Primeira geração de campo } \\
\hline & FOR & APO & UTA* & NTU* & MAS & MAM* \\
\hline Eliza x Shepody & 0,01 & 0,01 & 0,13 & $-1,47$ & $-22,34$ & 6,88 \\
\hline Eliza x Asterix & 0,03 & $-0,09$ & $-0,57$ & 1,57 & 54,35 & $-2,64$ \\
\hline Eliza x White Lady & $-0,18$ & $-0,02$ & 0,29 & 0,04 & $-13,60$ & $-2,23$ \\
\hline Eliza x Caesar & 0,14 & 0,11 & 0,15 & $-0,14$ & $-18,41$ & $-2,01$ \\
\hline C1730-7-94 x Shepody & $-0,24$ & 0,08 & $-0,28$ & 1,32 & $-9,42$ & $-7,88$ \\
\hline C1730-7-94 x Asterix & 0,18 & $-0,19$ & 0,06 & $-0,05$ & 15,28 & 2,53 \\
\hline C1730-7-94 x White Lady & 0,03 & 0,02 & 0,32 & $-1,53$ & $-36,22$ & 3,97 \\
\hline C1730-7-94 x Caesar & 0,03 & 0,08 & $-0,10$ & 0,26 & 30,36 & 1,38 \\
\hline C1742-8-95 x Shepody & 0,23 & $-0,09$ & 0,16 & 0,15 & 31,76 & 1,00 \\
\hline C1742-8-95 x Asterix & $-0,21$ & 0,28 & 0,51 & $-1,52$ & $-69,63$ & 0,11 \\
\hline C1742-8-95 x White Lady & 0,15 & 0,00 & $-0,62$ & 1,49 & 49,82 & $-1,74$ \\
\hline C1742-8-95 x Caesar & $-0,17$ & $-0,19$ & $-0,05$ & $-0,12$ & $-11,95$ & 0,63 \\
\hline
\end{tabular}

'FOR: formato; APO: apontado; UTA: uniformidade de tamanho; NTU: número de tubérculos; MAS: massa de tubérculos; MAM: massa média de tubérculos.

*Significativo a $5 \%$ pelo teste $\mathrm{t}$. 
desempenho, principalmente para profundidade de olho, sobrancelha, uniformidade de tamanho e uniformidade de formato de tubérculo, sendo 'White Lady' destaque, quanto à CGC para uniformidade de tamanho e de formato; portanto, esse cruzamento poderia ser recomendado. Os maiores valores de CEC, principalmente, para profundidade de olho, sobrancelha e uniformidade de formato foram obtidos com o cruzamento 'C1730-7-94 x Caesar'. Embora 'Caesar' tenha apresentado elevada CGC para profundidade de olho e sobrancelha, o cruzamento deve ser visto com cautela, pois, esse genitor, conforme visto anteriormente, não é um bom genitor para outros caracteres relacionados com aparência. Por outro lado, no cruzamento 'C1742-8-95' x ‘Asterix', que se destacou em relação à CEC para os caracteres curvatura, apontamento, uniformidade de tamanho e achatamento de tubérculo, os maiores valores de CGC foram observados apenas para curvatura, no caso de 'Asterix', e uniformidade de tamanho, para o genitor 'C1742-8-95'. No entanto, 'Asterix' fez parte dos cruzamentos com maior número de CEC indesejáveis para caracteres de aparência, principalmente quando combinada com 'Eliza' e 'C1730-7-94'. Assim, pode-se verificar que o cruzamento ‘C1730-7-94' x ‘White Lady' seria a combinação mais indicada para a geração de famílias superiores para caracteres de aparência.

Em relação aos caracteres componentes do rendimento de tubérculos (número, massa e massa média), da mesma forma que para CGC, foram observadas estimativas significativas para CEC (Tabelas 5 e 6). Diversos autores também verificaram significância, de ambas as capacidades de combinação, para massa de tubérculo em batata (Barbosa \& Pinto, 1998; Bradshaw \& Mackay, 1994; Mullin \& Lauer, 1966), e para NTU e MAM (Barbosa \& Pinto, 1998). Estimativas significativas apenas da CEC, foram relatadas por Plaisted et al. (1962), para rendimento de tubérculos, e por Killick (1977), para massa, número e massa média de tubérculos, e estimativas apenas de CGC foram observadas por Maris (1989), para massa, número e mas-

Tabela 6. Capacidade específica de combinação de sete genitores de batata para caracteres de aparência e de produtividade de tubérculos avaliados na geração de plântula e primeira geração de campo, em Canoinhas, SC

\begin{tabular}{|c|c|c|c|c|c|c|c|c|}
\hline \multirow{3}{*}{ Cruzamento } & \multicolumn{8}{|c|}{ Caracteres } \\
\hline & \multicolumn{8}{|c|}{ Geração de plântula } \\
\hline & FOR $* 1$ & UFO* & $\mathrm{ACH}^{*}$ & APA & & NTU* & MAS* & MAM* \\
\hline Eliza x Shepody & $-0,85$ & 0,10 & $-0,28$ & $-0,27$ & & 0,37 & 0,44 & $-0,34$ \\
\hline Eliza x Asterix & $-0,92$ & 0,87 & $-0,21$ & $-0,42$ & & $-0,57$ & 1,29 & 1,26 \\
\hline Eliza x White Lady & 1,62 & $-0,60$ & 0,07 & 0,40 & & 0,39 & $-0,68$ & $-0,52$ \\
\hline Eliza x Caesar & 0,15 & $-0,37$ & 0,42 & 0,29 & & $-0,19$ & $-1,05$ & $-0,39$ \\
\hline C1730-7-94 x Shepody & 0,71 & $-0,40$ & 0,26 & 0,29 & & $-0,74$ & $-2,05$ & $-0,05$ \\
\hline C1730-7-94 x Asterix & 1,06 & $-0,68$ & $-0,23$ & $-0,04$ & & 0,06 & $-0,81$ & $-0,57$ \\
\hline C1730-7-94 x W. Lady & $-1,13$ & 0,68 & $-0,11$ & 0,00 & & 0,44 & 3,36 & 0,91 \\
\hline C1730-7-94 x Caesar & $-0,64$ & 0,40 & 0,09 & $-0,25$ & & 0,23 & $-0,50$ & $-0,30$ \\
\hline C1742-8-95 x Shepody & 0,15 & 0,30 & 0,02 & $-0,02$ & & 0,37 & 1,61 & 0,39 \\
\hline C1742-8-95 x Asterix & $-0,14$ & $-0,19$ & 0,44 & 0,46 & & 0,51 & $-0,47$ & $-0,69$ \\
\hline C1742-8-95 x W. Lady & $-0,50$ & $-0,08$ & 0,04 & $-0,40$ & & $-0,83$ & $-2,68$ & $-0,39$ \\
\hline \multirow[t]{3}{*}{ C1742-8-95 x Caesar } & 0,49 & $-0,04$ & $-0,51$ & $-0,04$ & & $-0,04$ & 1,54 & 0,69 \\
\hline & \multicolumn{8}{|c|}{ Primeira geração de campo } \\
\hline & FOR & UFO & APO & CUR & $\mathrm{ACH}$ & NTU* & MAS* & MAM* \\
\hline Eliza x Shepody & $-0,18$ & $-0,04$ & $-0,02$ & 0,23 & 0,08 & 0,66 & 6,64 & $-7,52$ \\
\hline Eliza x Asterix & 0,35 & 0,44 & $-0,10$ & $-0,34$ & $-0,01$ & 0,36 & 33,30 & $-0,05$ \\
\hline Eliza x White Lady & 0,45 & $-0,05$ & 0,18 & 0,16 & $-0,05$ & $-0,67$ & $-37,20$ & 1,57 \\
\hline Eliza x Caesar & $-0,62$ & $-0,35$ & $-0,06$ & $-0,05$ & $-0,02$ & $-0,35$ & $-2,74$ & 6,00 \\
\hline C1730-7-94 x Shepody & $-0,07$ & 0,17 & 0,18 & $-0,01$ & $-0,05$ & 0,23 & 73,66 & 13,46 \\
\hline C1730-7-94 x Asterix & 0,08 & 0,08 & $-0,14$ & 0,05 & $-0,03$ & $-0,38$ & 24,82 & 7,36 \\
\hline C1730-7-94 x W. Lady & $-0,35$ & 0,00 & $-0,54$ & $-0,22$ & $-0,06$ & 0,66 & 22,83 & $-4,87$ \\
\hline C1730-7-94 x Caesar & 0,34 & $-0,25$ & 0,50 & 0,19 & 0,14 & $-0,51$ & $-121,31$ & $-15,95$ \\
\hline C1742-8-95 x Shepody & 0,25 & $-0,13$ & $-0,16$ & $-0,21$ & $-0,03$ & $-0,89$ & $-80,30$ & $-5,94$ \\
\hline C1742-8-95 x Asterix & $-0,43$ & $-0,52$ & 0,23 & 0,30 & 0,04 & 0,02 & $-58,12$ & $-7,31$ \\
\hline C1742-8-95 x W. Lady & $-0,10$ & 0,05 & 0,36 & 0,06 & 0,11 & 0,01 & 14,37 & 3,30 \\
\hline C1742-8-95 x Caesar & 0,28 & 0,60 & $-0,43$ & $-0,14$ & $-0,12$ & 0,86 & 124,05 & 9,95 \\
\hline
\end{tabular}

${ }^{1}$ FOR: formato; UFO: uniformidade de formato; ACH: achatamento; APA: aparência; APO: apontamento; CUR: curvatura; NTU: número de tubérculos; MAS: massa de tubérculos; MAM: massa média de tubérculos.

*Significativo a $5 \%$ pelo teste $\mathrm{t}$. 
sa média de tubérculos. Portanto, para esses caracteres, a predominância de CGC ou CEC depende do material genético e das combinações utilizadas.

Pode-se presumir a dificuldade para obtenção de um equilíbrio dos três caracteres de rendimento, pois, geralmente, plantas com maior número de tubérculos tendem a produzir tubérculos menores (Maris, 1988; Gaur \& Kishore, 1978; Rodrigues \& Pereira, 2003; Silva et al. 2007). A relação entre massa e número de tubérculos é muito importante, pela influência que exerce no rendimento de tubérculos comerciais. No grupo 1, não foi possível identificar genitores superiores e com estabilidade, para os locais e gerações de avaliação (Tabelas 5 e 6). No entanto, destacam-se os cruzamentos 'Eliza' $x$ 'Asterix', 'C1730-7-94' x ‘White Lady' e 'C1742-8-95' x 'Caesar'. O primeiro cruzamento apresentou valores variáveis, para os locais e gerações, em relação aos caracteres número e massa média de tubérculos, e superioridade para massa de tubérculos. $\mathrm{O}$ segundo cruzamento destacou-se pela CEC para massa e massa média de tubérculos, consistentemente, nos locais e gerações avaliados, e, em relação à massa de tubérculos, ambos contribuíram com maiores valores de CGC, podendo esta combinação ser recomendada. O terceiro cruzamento também se destacou, em relação à CEC, para massa e massa média de tubérculos; porém, nem 'C1742-8-95', nem 'Caesar' apresentaram alta CGC.

\section{CONCLUSÕES}

Há predominância de efeitos aditivos no controle dos caracteres avaliados. 'White Lady' é o genitor que mais contribui com genes de ação aditiva para a melhoria, tanto dos caracteres que compõem a aparência dos tubérculos, quanto para caracteres de rendimento.

O cruzamento ('C1730-7-94' x 'White Lady’) é o mais indicado para a geração de famílias superiores quanto aos caracteres de aparência e caracteres componentes do rendimento de tubérculos.

\section{AGRADECIMENTOS}

Ao CNPq, pelo auxílio financeiro ao Programa de Melhoramento Genético de Batata da Embrapa.

\section{REFERÊNCIAS}

Barbosa MHP \& Pinto CABP (1998) Análise dialélica parcial entre cultivares de batata nacionais e introduzidas. Pesquisa Agropecuária Brasileira, 33:307-320.

Bradshaw JE \& Mackay GR (1994) Breeding strategies for clonally propagated potatoes. In: Bradshaw JE \& Mackay GR (Eds.) Potato genetics. Wallingford, CAB International. p.467-497.

Campos H de (1983) Estatística experimental não-paramétrica. $4^{\mathrm{a}}$ ed. Piracicaba, FEALQ. 349p.
Castiglioni VBR, Oliveira MF de \& Arias CAA (1999) Análise da capacidade combinatória entre linhagens de girassol. Pesquisa Agropecuária Brasileira, 34:981-988.

Comstock RE \& Robinson HF (1948) The components of genetic variance in populations. Biometrics, 4:254-266.

Cruz CD (2006) Programa Genes: biometria. Viçosa, Universidade Federal de Viçosa. 382p.

Cruz CD, Regazzi AJ \& Carneiro PC (2004) Métodos biométricos aplicados ao melhoramento genético. Viçosa, Universidade Federal de Viçosa. 480p.

Gaur PC \& Kishore H (1978) Studies on character association in potatoes. Journal Agriculture Science, 90:215-219.

Gopal J (1998) Identification of superior parents and crosses in potato breeding programmes. Theoretical Applied Genetics, 96:287-293

Griffing B (1956) Concept of general and specific combining ability in relation to diallel crossing systems. Australian Journal of Biological Sciences, 9:463-493.

Jaramillo G, Morante N, Perez JC, Calle F, Ceballos H, Arias B \& Bellotti AC (2005) Diallel analysis in cassava adapted to the midaltitude valleys environment. Crop Science, 45:1058-1062.

Killick RJ (1977) Genetic analysis of several traits in potatoes by means of a diallell cross. Annals of Applied Biology, 86:279289.

Maris B (1988) Correlations within and between characters between and within generations as a measure for the early generation selection in potato breeding. Euphytica, 37:205-209.

Maris B (1989) Analysis of an incomplete diallel cross among three ssp. tuberosum varieties and seven long-day adapted ssp. andigena clones of the potato (Solanum tuberosum L.). Euphytica, 41:163-182.

Mullin R \& Lauer FI (1966) Breeding behavior of F1 and inbred potato clones. American Society Horticulture Science, 89:449455 .

Neele AEF, Nab HJ \& Louwes KM (1991) Identification of superior parents in a potato breeding programme. Theoretical and Applied Genetics, 82:264-272.

Plaisted RL, Sandford L, Federer WT, Kehr AE \& Peterson LC (1962) Specific and general combining ability for yield in potatoes. American Potato Journal, 39:185-197.

Rodrigues AFS \& Pereira AS (2003) Correlações inter e intragerações e herdabilidade de cor de chips, matéria seca e produção em batata. Pesquisa Agropecuária Brasileira, 38:599604.

Silva GO, Pereira AS, Souza VQ, Carvalho FIF \& Fritsche Neto R (2007) Correlações entre caracteres de aparência e rendimento e análise de trilha para aparência de batata. Bragantia, 66:381388 .

Silva GO, Pereira AS, Souza VQ, Carvalho FIF \& Vieira EA (2008) Capacidade de combinação multivariada para caracteres de tubérculo em gerações iniciais de seleção em batata. Ciência Rural, 38:321-325.

Silva GO, Pereira AS, Souza VQ, Carvalho FIF \& Neto RF (2009) Estimativa de capacidades de combinação em gerações iniciais de seleção de batata. Horticultura Brasileira, 27:275-279.

Steel RGD \& Torrie JH (1980) Principles and procedures of statistics. $2^{\text {a }}$ ed. New York, McGraw-Hill Book. 633p.

Tai GCC (1976) Estimation of general and specific combining abilities in potatoes. Canadian Journal of Genetics and Cytology, 18:385-394. 